\title{
Evidence of person-to-person transmission within a family cluster of novel coronavirus infections, United Kingdom, February 2013
}

The Health Protection Agency (HPA) UK Novel Coronavirus Investigation team (Richard.Pebody@hpa.org.uk)

1. The members of the team are listed at the end of the article

Citation style for this article:

The Health Protection Agency (HPA) UK Novel Coronavirus Investigation team. Evidence of person-to-person transmission within a family cluster of novel coronavirus infections, United Kingdom, February 2013. Euro Surveill. 2013;18(11):pii=20427. Available online: http://www.eurosurveillance.org/ViewArticle. aspx?Articleld $=20427$

Article submitted on 05 March 2013 /published on 14 March 2013

In February 2013, novel coronavirus (nCoV) infection was diagnosed in an adult male in the United Kingdom with severe respiratory illness, who had travelled to Pakistan and Saudi Arabia 10 days before symptom onset. Contact tracing identified two secondary cases among family members without recent travel: one developed severe respiratory illness and died, the other an influenza-like illness. No other severe cases were identified or $\mathrm{nCoV}$ detected in respiratory samples among 135 contacts followed for 10 days.

On 8 February 2013, the Health Protection Agency (HPA) in London, United Kingdom (UK), confirmed infection with novel coronavirus ( $\mathrm{nCoV}$ ) in a patient in an intensive care unit, who had travelled to both Pakistan and Saudi Arabia in the 10 days before the onset of symptoms [1]. This patient (hereafter referred to as Case 1) was the 1oth confirmed case reported internationally of a severe acute respiratory illness caused by $\mathrm{nCoV}$. Two secondary cases of $\mathrm{nCoV}$ were subsequently detected. We describe the public health investigation of this cluster and the clinical and virological follow-up of their close contacts.

The nCoV was first described in September 2012 in a Saudi Arabian national who died in June 2012 [2,3]. The UK detected its first case of nCoV infection in a male foreign national transferred from Qatar to London in September 2012 [4]. By February 2013, a total of two clusters had been described globally: one cluster $(n=2)$ among staff in a hospital in Jordan and a family cluster $(n=3)$ in Saudi Arabia [5]. No clear evidence of personto-person transmission was documented in either cluster [6].

\section{Index case exposure history and}

laboratory investigations

The index case was a middle-aged UK resident, who had travelled to Pakistan for five weeks. He then travelled directly to Saudi Arabia on 20 January where he remained until his return to the UK on 28 January 2013. During his stay in Saudi Arabia, he spent time in Mecca and Medina on pilgrimage. On 24 January, while in Saudi Arabia, he developed fever and upper respiratory tract symptoms (Figure 1). No direct contact with animals or with persons with severe respiratory illness was reported in the 10 days before the onset of illness.

When back in the UK, the patient's respiratory symptoms worsened and he visited his GP on 30 January; he was admitted to hospital on 31 January. He rapidly deteriorated and required invasive ventilation for respiratory support. Due to further deterioration, he needed extracorporeal membrane oxygenation (ECMO) and was thus transferred to a tertiary centre on 5 February, where he remains severely ill on ECMO as of 1 March.

Initial laboratory investigation included a respiratory virus screen, with confirmation of influenza A infection on 1 February. This was subsequently characterised as influenza $A\left(\mathrm{H}_{1} \mathrm{~N}_{1}\right)$ pdmo9. As the patient's clinical condition failed to improve following administration of influenza-specific antiviral drugs, he was subsequently investigated for $\mathrm{nCoV}$ infection in line with HPA guidance [7]. On 7 February, nCoV was detected initially in a throat swab with a real-time PCR assay at a local laboratory, and nCoV was confirmed on 8 February by the HPA Respiratory Virus Reference Unit.

\section{Public health management}

Following the confirmation of this imported nCoV case, the UK public health authorities implemented enhanced infection control measures to minimise possible onward transmission of infection: identification and follow-up of contacts to investigate whether transmission had occurred and prompt diagnosis and appropriate management of any further cases. The HPA protocol for investigation of $\mathrm{nCoV}$ cases and their close contacts was used [8]. For the purpose of the investigation, a close contact was defined as: 


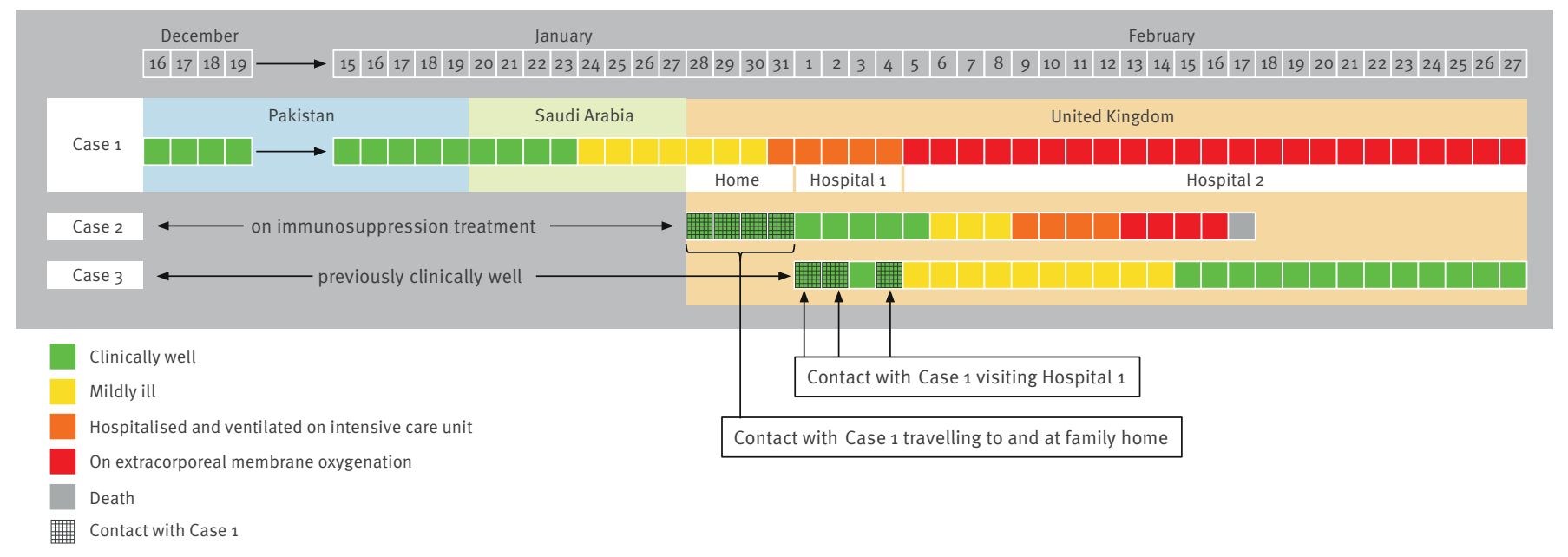

- Aeroplane setting: the aircraft passengers in the same row and the two rows in front and behind a symptomatic case;

- Household setting: any person who had prolonged (>15 minutes) face-to-face contact with the confirmed case(s) any time during the illness in a household setting;

- Healthcare setting: either (i) a worker who provided direct clinical or personal care to or examined a symptomatic confirmed case or was within close vicinity of an aerosol-generating procedure AND who was not wearing full personal protective equipment (PPE) at the time; or (ii) a visitor to the hospital who was not wearing PPE at the bedside of a confirmed case; full PPE was defined as correctly fitted high filtration mask ( $\mathrm{FFP}_{3}$ ), gown, gloves and eye protection;

- Other setting: any person who had prolonged (>15 minutes) face-to-face contact with a confirmed symptomatic case in any other enclosed setting.

Identification and follow-up of individuals who had close contact with the index case from entry into the UK at any time during his symptomatic period was rapidly initiated by the HPA together with staff from the two hospitals the patient had attended (including the Infection Prevention and Control Teams and Occupational Health).

Close contacts were followed up for a minimum period of 10 days after last exposure to the index case. Following the identification of two secondary $\mathrm{nCoV}$ cases among symptomatic family contacts of the index case, contact tracing was initiated for their respective additional contacts. Follow-up included collection of information on the date and setting of contact with the index case, PPE use (healthcare workers) and any symptoms of respiratory infection in the 10 days after last exposure. Contacts who developed any symptoms of acute respiratory infection in this period were asked to self-isolate in their homes (or were isolated in hospital if admitted) until asymptomatic.

The airline provided details of passengers to the HPA to allow follow-up of those persons in the same row as the case and the two adjacent rows to the patient as per World Health Organization (WHO) guidance for severe acute respiratory syndrome (SARS) [9]. Passengers who were in the UK were followed up by the HPA to inform them of the potential exposure and determine whether they had developed symptoms of acute respiratory illness in the 10 days post exposure. UK authorities informed relevant overseas national authorities directly about non-UK resident contacts on the flight through International Health Regulation mechanisms.

\section{Laboratory investigation}

Symptomatic contacts had respiratory samples taken (nose and throat swab, and sputum if they had a productive cough) for testing for a panel of respiratory viruses (influenza virus, respiratory syncytial virus, parainfluenza virus types $1,2,3$ and 4, adenovirus, rhinovirus, human metapneumovirus) and for $\mathrm{nCoV}$. Criteria for laboratory confirmation of $\mathrm{nCoV}$ were Up $\mathrm{E}$ real-time PCR detection in two different laboratories [3] and detection of two other regions of the $\mathrm{nCoV}$ genome [3, HPA unpublished data].

In addition, nose and throat swabs were taken from a group of asymptomatic contacts of the three confirmed cases for nCoV testing to determine if there was evidence of asymptomatic carriage.

Paired serum samples are being taken from all household and healthcare contacts regardless of symptoms 
Outcome of contact ${ }^{\mathrm{a}}$ follow-up for 10 days after last exposure to index case for respiratory illness and nCoV infection, after entry to the United Kingdom, February 2013 (n=92)

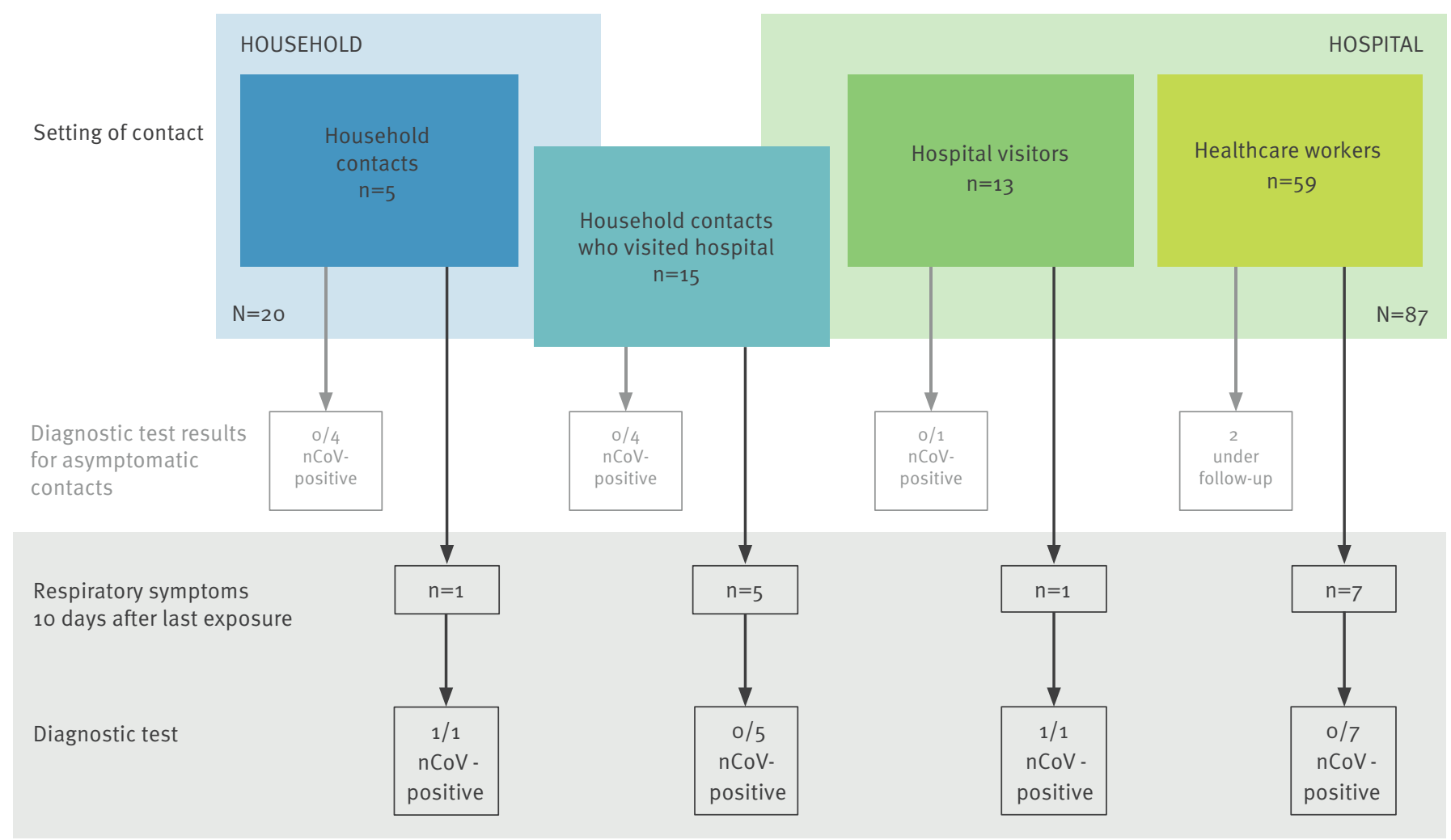

${ }^{a}$ Excluding flight contacts.

with the initial sample taken within seven days of last exposure and the second at least 21 days after the first. Once collected, samples will be tested for serological reactivity to $\mathrm{nCoV}$.

\section{Initial epidemiological investigation of cluster}

By 28 February, tracing of contacts of the index case (Case 1) had identified 103 close contacts in the UK, including 59 healthcare workers in the two hospitals, 20 household contacts of whom 15 also visited him at the hospital, 13 family and friends who visited the case in hospital, and 11 contacts during the flight who were UK residents or nationals. In addition there were nine non-UK flight contacts.

Based on available information, a number of healthcare workers with direct contact with Case 1 did not have full PPE, e.g. were not wearing an $\mathrm{FFP}_{3}$ mask. Seven of 59 healthcare workers developed mild, self-limiting respiratory symptoms in the 10 days after last contact. The $\mathrm{nCoV}$ was not detected by PCR in the respiratory samples of any of these seven symptomatic contacts (Figure 2).

Six of the 20 household contacts of the index case developed acute respiratory symptoms in the 10 days since last exposure, of whom one progressed to severe illness requiring hospitalisation. This single hospitalised contact was subsequently confirmed to have $\mathrm{nCoV}$ infection (hereafter referred to as Case 2), and was also positive for type 2 parainfluenza virus. The remaining five symptomatic household contacts had mild self-limiting disease, and $\mathrm{nCoV}$ was not detected from their respiratory samples nor in any of the asymptomatic household contacts of Case 1 that were tested (Figure 2).

One of the 13 non-household contacts visiting Case 1 at the hospital, hereafter referred to as Case 3, 
Outcome of contact follow-up for 10 days after last exposure to Case 2 (secondary case) for respiratory illness and nCoV infection, United Kingdom, February $2013(\mathrm{n}=18$ )

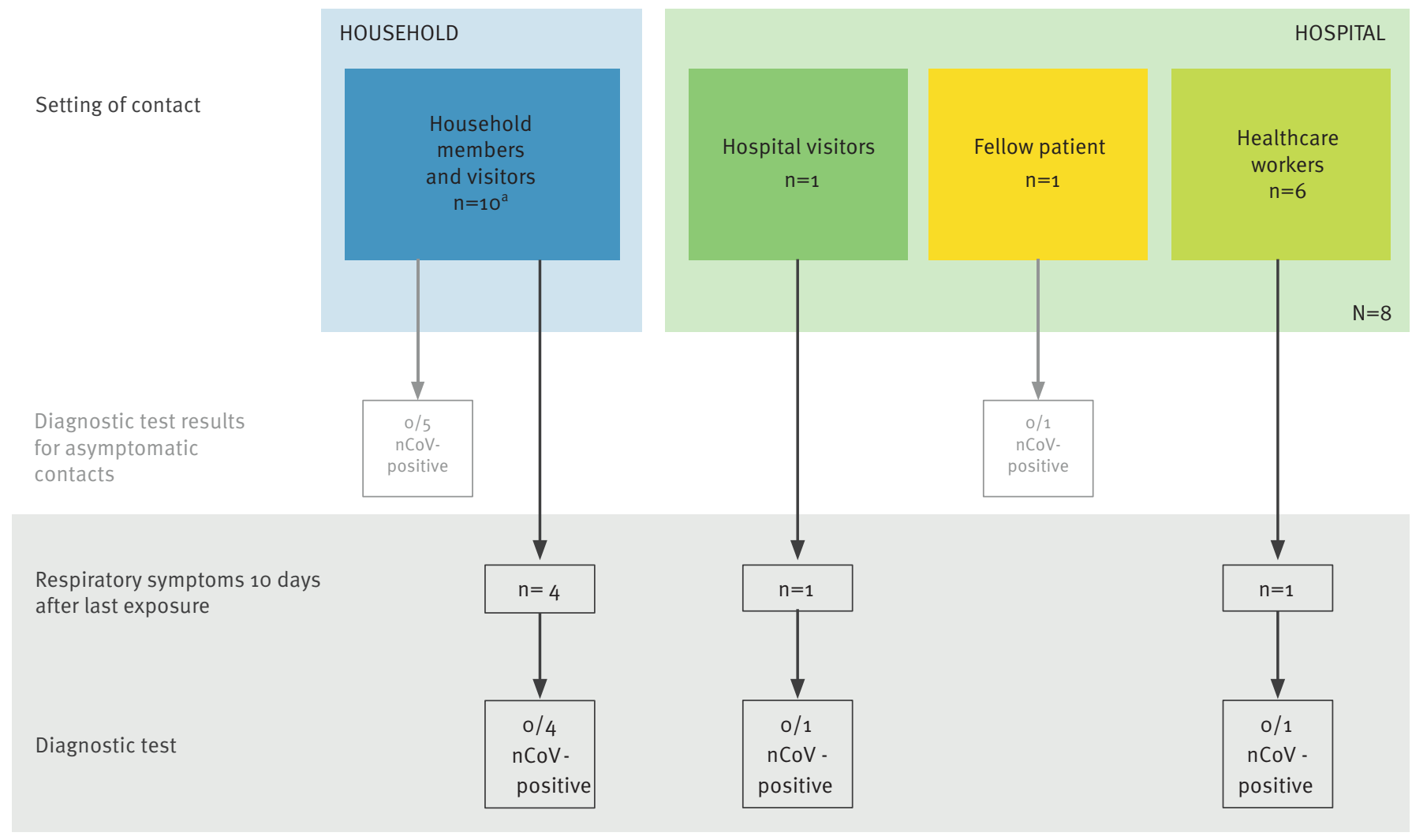

a 10/10 household members and visitors also had contact with Case 1, 2/10 also had contact with Case 3 .

developed an acute mild, respiratory illness, and $\mathrm{nCoV}$ was detected in a respiratory sample, as was type 2 parainfluenza virus.

Two of the 11 UK-based passengers reported respiratory symptoms: one had recovered by the time of interview and did not have respiratory samples taken. In the other, nCoV was not detected from respiratory samples.

The periods of exposure of Case 2 and Case 3 to Case 1 and the timelines of their illnesses are represented in Figure 1.

\section{Case 2 and his contacts}

Case 2 was a male household member, who had an underlying malignant condition, the treatment of which is likely to have resulted in immunosuppression. He had not travelled overseas. Contact with the index case in a household setting occurred from the arrival of Case 1 in the UK until Case 1 was admitted to hospital on 31 January. Case 2 reportedly became unwell on 6 February and was admitted to hospital on 9 February. He required intensive care and ECMO treatment. In a nose and throat swab taken on 10 February, nCoV and type 2 parainfluenza virus were detected. His respiratory condition deteriorated and he died on 17 February.

A number of household contacts (four of 10), hospital visitors (one of one) and healthcare contacts (one of six) of Case 2 developed mild self-limiting respiratory illness in the 10 days after last exposure. In addition, case 2 had one neighbouring patient contact in the hospital, who did not develop symptoms. None had $\mathrm{nCoV}$ detected in respiratory samples (Figure 3).

\section{Case 3 and her contacts}

Case 3 is an adult female family member of Case 1 who lived in a different household and had not recently travelled abroad. She was exposed to Case 1 only while visiting him in hospital on three separate occasions from 
Outcome of contact follow-up for 10 days after last exposure to Case 3 (secondary case) for respiratory illness and nCoV infection, United Kingdom, February 2013 (n=25)

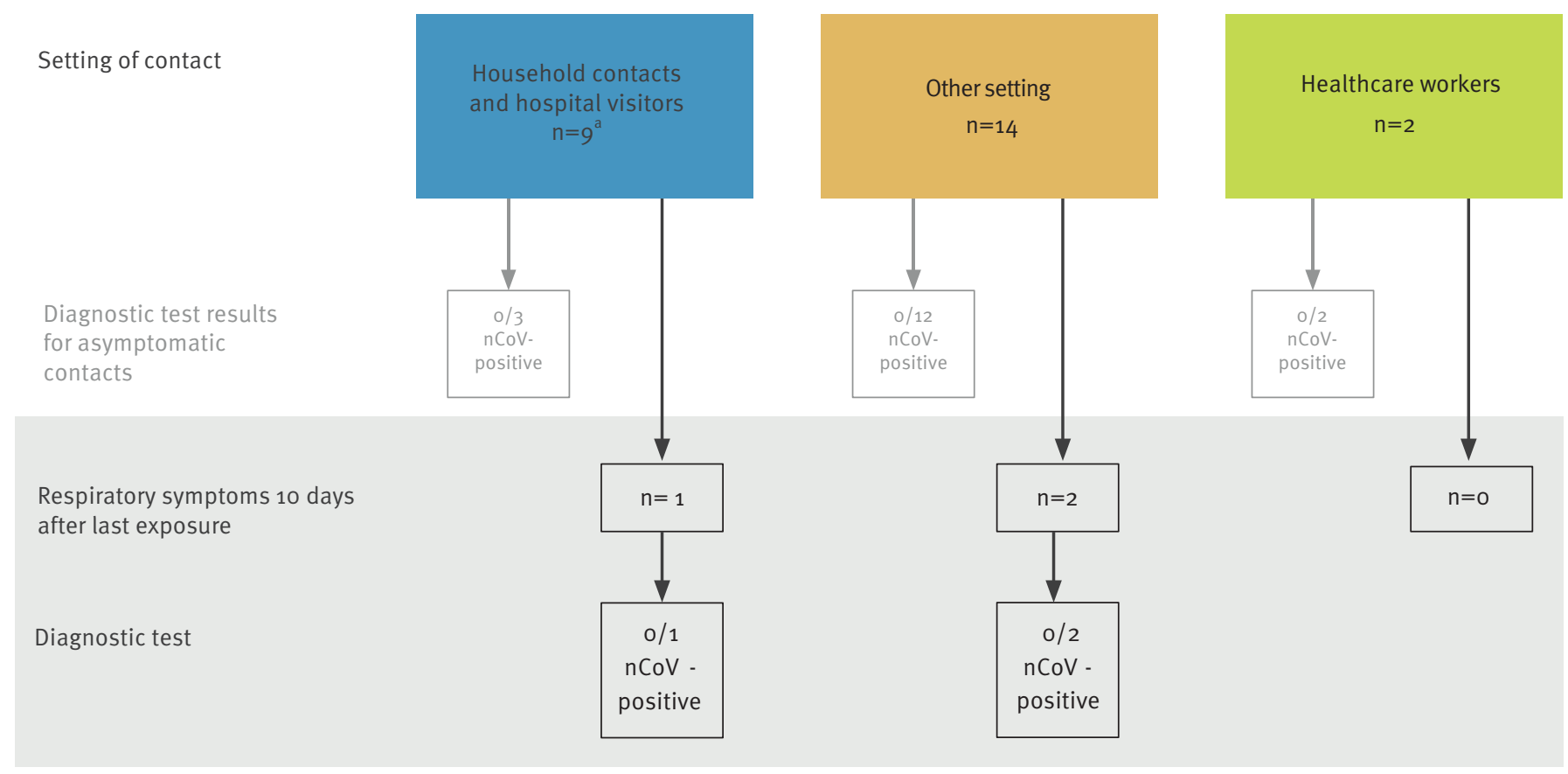

a 2/9 household members and visitors also had contact with Case 2.

1 to 4 February for a cumulative period of 2.5 hours, during which full PPE was not worn. During these visits Case 1 was intubated on a closed ventilator circuit. Case 3 had no contact with Case 2 while he was unwell. Case 3 developed a self-limiting influenza-like illness starting on 5 February, one day after her last contact with Case 1. She did not require medical attendance for her illness and fully recovered after nine days. She tested positive for $\mathrm{nCoV}$ on a single sputum sample taken on 13 February and positive for type 2 parainfluenza virus on a nose and throat swab taken on 15 February. Serology results are awaited.

A total of 25 close contacts of Case 3 were identified (nine household contacts, 14 other contacts, and two healthcare workers) of whom three developed mild self-limiting respiratory illness in the 10 days post exposure. None of these, nor the asymptomatic contacts that were tested, were found to have $\mathrm{nCoV}$ in respiratory samples (Figure 4).

Of the 44 contacts of Cases 1, 2 and 3 who were swabbed, 11 had another respiratory virus detected in respiratory samples: rhinovirus $(n=7)$, influenza $A\left(\mathrm{H}_{3}\right)$ and type 2 parainfluenza virus $(n=1)$, type 2 parainfluenza virus $(n=1)$, type 3 parainfluenza virus $(n=1)$ and metapneumovirus $(n=2)$.

\section{Public health implications}

We present evidence of limited person-to-person transmission of $\mathrm{nCoV}$ following contact with an index case returning to the UK from travel to Pakistan and Saudi Arabia. Neither of the two secondary cases that were detected had recently travelled and must therefore have acquired their infection in the UK. Both were extended family members and reported contact with the index case. One probably acquired the infection in a household setting and the other while visiting the index case in hospital. The nCoV was not detected among an additional 92 close contacts of the index case, or among the close contacts of the two secondary cases. These findings suggest that although personto-person infection is possible, there is no evidence at present of sustained person-to-person transmission of $\mathrm{nCoV}$ in the UK in relation to this cluster. The limited transmissibility is consistent with the data available to date, with only two other reports of small, self-limited clusters of severe disease in the Middle East: one in a healthcare setting and the other in a household setting [5]. Furthermore, intensive follow-up of close contacts of two other cases imported to European countries has failed to demonstrate onward transmission $[10,11]$.

We found that the index case in this cluster was coinfected with influenza. Type 2 parainfluenza virus was 
detected in the two secondary cases. This raises questions about what roles these other infections might play in relation to $\mathrm{nCoV}$ transmissibility and/or the severity of the illness. In addition, as the index case was diagnosed initially with influenza, this lead to a delay in recognition of $\mathrm{nCoV}$. This highlights the importance of considering a diagnosis of $\mathrm{nCoV}$ in atypical cases (in this case the poor response to antiviral drugs), even if a putative alternative diagnosis has already been made. HPA guidance has been adapted accordingly [7].

Although the transmissibility patterns of $\mathrm{nCoV}$ and SARS have been different to date, confirmed cases of $\mathrm{nCoV}$ reported globally have suggested a clinical picture similar to SARS, in particular the presentation with severe respiratory illness, with nine of the 15 cases reported globally to date having died [12]. Two of the three cases we describe fit this clinical picture: two required ECMO treatment and one of them died. However, the third case presented with an acute selflimiting respiratory infection that did not require hospitalisation or medical attention. This first reported case of a milder nCoV illness raises the possibility that the spectrum of clinical disease maybe wider than initially envisaged, and that a significant proportion of cases now or in the future might be milder or even asymptomatic. This highlights the importance of intensive contact tracing and virological and serological follow-up around all confirmed cases of nCoV. The application of recently developed serological assays in one case-contact study did not provide evidence of asymptomatic infection, although the contacts investigated were exposed late in the case's illness, when the viral load might be lower [11]. Paired sera are being gathered from contacts in this current investigation to determine whether there may have been more widespread mild or asymptomatic infection.

The fact that the two secondary cases acquired their infection from an imported sporadic case has enabled a preliminary estimation of the incubation and serial intervals. The timing of onset of symptoms in the index and the two secondary cases and of exposure suggests a putative incubation period ranging from one to nine days and a serial interval (time between onset of illness in index case and secondary case) of 13 to 14 days. Although the data are extremely limited, the observed upper range of the incubation period is perhaps more similar to that seen for SARS (usual range: two to 10 days) rather than seasonal coronavirus infection (usual range: two to five days) [13]. It is therefore not possible to ascertain with certainty whether the index case acquired his infection in Saudi Arabia or in Pakistan, although previous $\mathrm{nCoV}$ cases have been linked to the Middle East. This highlights the importance of gathering more information to determine risk factors for acquisition of infection.

All confirmed $\mathrm{nCoV}$ cases detected to date, apart from the two secondary cases in the UK cluster, spent time in the Middle East during the putative incubation period. This, together with our observations of limited secondary transmission, highlights the importance of ongoing vigilance and rapid investigation of cases of severe respiratory illness in residents of and travellers from that area. Further work is required to determine how widely $\mathrm{nCoV}$ is circulating globally. In particular serological investigations are needed on the extent of recent infection in various populations, as well as virological investigation of cases of severe undiagnosed respiratory illness in settings both in and beyond the Middle East.

\section{Acknowledgements}

We would like to acknowledge Critical Care, Infection Prevention and Control and Occupational Health staff involved in patient care, and all health protection staff involved in the public health response.

Members of the

- HPA West Midlands East Health Protection Unit (HPU): Mamoona Tahir, Roger Gajraj, Madhu Bardhan, Huda Mohammed, Louise Dyke, Petra Charlemagne, Rea Alves.

- HPA West Midlands West HPU: David Kirrage, Dan Killalea, Kate James, Melinda Kemp.

- HPA West Midlands North HPU: Harsh Duggal, Robert Carr, Musarrat Afza, Nicholas Aigbogun, Bharat Sibal.

- HPA West Midlands Regional Epidemiology Unit: Ruth Harrell, Obaghe Edeghere, Keith Neal.

- HPA West Midlands Regional Director's Office: Sue Ibbotson.

- Birmingham City Hospital: Nimal Wickramasinghe, Nick Sherwood.

- University Hospitals Birmingham: Beryl Oppenheim, Louise Hopton.

- HPA Specialist Microbiology Network Public Health Laboratory Birmingham: Husam Osman, Erasmus Smit, Sowsan Atabani, Judith Workman, Steve Wilson, Clair Overton-Lewis, Margaret Logan.

- HPA Greater Manchester HPU: Rosemary McCann, Marko Petrovic, Vinay Bothra, William Welfare.

- University Hospital of South Manchester: Barbara Isalska, Julian Barker, Alan Ashworth, Igor Fedor.

- HPA North West London HPU: Claude Seng, Deepti Kumar.

- HPA South Yorkshire HPU: Suzanna Matthews.

- HPA London Regional Director's Office: Brian McCloskey.

- University of Nottingham: Jonathan Nguyen-Van-Tam.

- HPA Health Protection Services - Central Office: Paul Cosford.

- HPA Reference Microbiology Services: Alison Bermingham, Joanna Ellis, Monica Galiano, Angie Lackenby, Richard Myers, Robin Gopal, Maria Zambon.

- HPA Colindale Health Protection Services: *Richard Pebody, Lucy Thomas, Nicki Boddington, Helen K Green, Hongxin Zhao, Iain Kennedy, Ibrahim Abubakar, Jane Jones, Nick Phin, Mike Catchpole, John M Watson.

Conflict of interest

None declared.

Authors' contributions

The HPA HPU and regional teams and NHS hospital teams were responsible for the collection of data and samples 
on cases and their contacts. The HPA Microbiology service teams were responsible for testing and interpretation of results from respiratory samples. National co-ordination of the investigation including design, data collation and analysis was undertaken by the HPS Colindale team in collaboration with other team members. HPS Colindale were responsible for the initial draft of the article. All co-authors provided comments and approved the final version.

\section{References}

1. Novel coronavirus 2012 in the UK: situation at 19 February 2013. Health Protection Report. 2013;7(8). Available from: http://www.hpa.org.uk/hpr/archives/2013/hpro813.pdf

2. ProMED-mail. Novel coronavirus - Saudi Arabia:

human isolate. Archive Number: 20120920.1302733. 20 September 2012. Available from: http://www.promedmail. org $/$ ?archiveid $=302733$

3. Corman VM, Eckerle I, Bleicker T, Zaki A, Landt O, Eschbach Bludau $M$, et al. Detection of a novel human coronavirus by real-time reverse-transcription polymerase chain reaction. Euro Surveill. 2012;17(39):pii=20285. Available from: http:// www.eurosurveillance.org/ViewArticle.aspx?Articleld $=\mathbf{2 0 2 8 5}$

4. Bermingham A, Chand MA, Brown CS, Aarons E, Tong C, Langrish C, et al. Severe respiratory illness caused by a novel coronavirus, in a patient transferred to the United Kingdom from the Middle East, September 2012. Euro Surveill. 2012;17(40):pii=20290. Available from: http://www. eurosurveillance.org/ViewArticle.aspx?Articleld=20290

5. World Health Organization (WHO). Novel Coronavirus infection - update. Geneva: WHO; 30 Nov 2012. Available from: http:// www.who.int/csr/don/2012_11_30/en/index.html

6. European Centre for Disease prevention and Control (ECDC) Rapid risk assessment. Severe respiratory disease associated with a novel coronavirus. Stockholm: ECDC; 19 February 2013. Available from: http://www.ecdc.europa.eu/en/publications/ Publications/novel-coronavirus-rapid-risk-assessment-update. pdf

7. Health Protection Agency (HPA). HPS nCoV case algorithm. Version case_v13. London: HPA; 19 Feb 2013. Available from: http://www.hpa.org.uk/webc/HPAwebFile/ HPAweb_C/1317136270914

8. Health Protection Agency (HPA). "The First Few Hundred (FF10o)". Enhanced Case and Contact Protocol v4.0. Epidemiological Protocols for Comprehensive Assessment of Early Novel Coronavirus Cases and their close contacts in the United Kingdom. London: HPA. [Accessed: 19 Feb 2013]. Available from: http://www.hpa.org.uk/webc/HPAwebFile/ HPAweb_C/1317136300809

9. WHO recommended measures for persons undertaking international travel from areas affected by Severe Acute Respiratory Syndrome (SARS). Wkly Epidemiol Rec. 2003;78(14):97-9. PMid:12723281.

10. Pebody RG, Chand MA, Thomas HL, Green HK, Boddington $\mathrm{NL}$, Carvalho $\mathrm{C}$, et al. The United Kingdom public health response to an imported laboratory confirmed case of a novel coronavirus in September 2012. Euro Surveill. 2012;17(40):pii=20292. Available from: http://www. eurosurveillance.org/ViewArticle.aspx?Articleld =20292

11. Buchholz U, Müller MA, Nitsche A, Sanewski A, Wevering N, Bauer-Balci T, et al. Contact investigation of a case of human novel coronavirus infection treated in a German hospital, October-November 2012. Euro Surveill. 2013;18(8):pii=20406. Available from: http://www.eurosurveillance.org/ViewArticle. aspx?Articleld=20406. PMid:23449231.

12. World Health Organization (WHO). Novel coronavirus update. Geneva: WHO; 12 Mar 2013. Available from: http://www.who. int/csr/don/2013_03_12/en/index.html

13. Lessler J, Reich NG, Brookmeyer R, Perl TM, Nelson KE, Cummings DA. Incubation periods of acute respiratory viral infections: a systematic review. Lancet Infect Dis. 2009;9(5):291-300. http://dx.doi.org/10.1016/ S1473-3099(09)70069-6. 